\title{
PENERAPAN ALGORITMA EA-SHORT PADA PROTOKOL ROUTING AOMDV UNTUK MENEMUKAN RUTE HANDAL BERBASIS ENERGI DI JARINGAN MANET
}

\author{
(Application of EA-SHORT Algorithm on AOMDV Routing Protocol to Find Reliable \\ Energy Based Routes in Manet Networks)
}

\author{
B. Nurwahyu Hairani, Andy Hidayat Jatmika*, Fitri Bimantoro \\ Program Studi Teknik Informatika, Fakultas Teknik, Universitas Mataram \\ JI. Majapahit 62, Mataram, Lombok NTB, INDONESIA \\ Email: baiqhaira22@gmail.com, [andy, bimo]@unram.ac.id
}

\begin{abstract}
Mobile Ad Hoc Network (MANET) is a stand-alone wireless network, consisting of several nodes that can move in all directions freely. The routing protocol used as the object of this study is AOMDV. This research carries out an energy calculation process at a node that can be used as a new energy-based route by utilizing topology changes. Energy efficiency in the routing protocol can be done using the Energy-Aware SHORT (EA-SHORT) method. The main purpose of the EA-SHORT algorithm is to distribute the traffic load of each node on MANET fairly, by extending the life of the node and network by routing packets through nodes that have enough remaining power and avoiding nodes that have low power. AOMDV performance will be compared with AOMDV which has been modified with EA-SHORT measured from the specified parameter values. Analysis results show that the application of the EA-SHORT algorithm in the efficiency of route search succeeded in improving performance. The results of throughput on EA-AOMDV increased by $13.904 \%$ for an area of $500 \times 500 \mathrm{~m} 2$ and $13.905 \%$ at $1000 \times 1000 \mathrm{~m} 2$. The packet delivery ratio increased by $0.91 \%$ and $2.273 \%$. Average end-to-end delay decreased by $20.482 \%$ and $18.734 \%$.
\end{abstract}

Keywords: MANET, AOMDV, Energy aware SHORT, EA-AOMDV, Routing protocol

*Penulis Korespondensi

\section{Pendahuluan}

Mobile Ad Hoc Network (MANET) ialah jaringan nirkabel yang berdiri sendiri, terdiri dari sejumlah node yang mampu bergerak ke segala arah secara bebas. Akibat pergerakan yang bebas tersebut topologi jaringan MANET cenderung sering berubah [1]. Nodenode pada jaringan MANET terdiri dari node sumber sebagai pengirim dan node tujuan sebagai penerima, dan antar node pengirim dan penerima disebut node tengah yang berfungsi sebagai perantara kedua node tersebut. Masing-masing node pada jaringan MANET memiliki level yang sama, artinya semua node berperan sebagai router [2].

Dalam hal komunikasi antar node, perlu adanya proses routing. Proses ini biasanya dikerjakan oleh suatu protokol routing agar node-node mampu saling berkirim data. Pada penelitian ini objek yang digunakan adalah protokol routing Ad Hoc On-Demand Multipath Distance Vektor (AOMDV). AOMDV merupakan protokol routing yang bersifat reaktif AOMDV memiliki mekanisme route discovery dan route maintenance [2].
Pencarian rute pada protokol routing AOMDV dilakukan dengan cara memperhitungkan jarak berdasarkan jumlah hop. Apabila pada routing table sudah tidak ada rute cadangan lagi, maka AOMDV akan melakukan pencarian rute kembali dari awal. Pada AOMDV adanya perpindahan rute menyebabkan banyak terjadi paket data drop dalam proses transisi antar rute. Sehingga sangat diperlukan rute yang stabil untuk mengatasi masalah akibat mobilitas node tersebut. Perubahan topologi dan mobilitas node dapat mengakibatkan rute memiliki kemungkinan terputus yang disebabkan node keluar dari jangkauan sinyal transmisi [4]. Namun di sisi lain perubahan topologi ini dapat dimanfaatkan untuk melakukan redirection agar mendapatkan rute baru yang handal dengan menghitung aspek energi pada node. Sehingga diharapkan mampu meningkatkan throughput dan menurunkan delay.

Setiap wireless mobile device pada MANET eksistensinya dibatasi oleh adanya ketersediaan energi. Bila energi sebuah wireless mobile device habis, maka wireless mobile device tersebut tidak eksis lagi pada 
MANET [5]. Keterbatasan energi terjadi karena setiap node selalu bergantung kepada energi yang terbatas yang dimilikinya dalam rangka menyelesaikan tugas utamanya. Masalah yang dapat dilihat yakni skalabilitas dalam kebijakan overhead yang berimbas pada jumlah node yang beroperasi di jaringan, juga terkait erat dengan konsumsi energi karena jumlah paket kontrol yang lebih tinggi berarti lebih banyak konsumsi energi yang dihabiskan dalam transmisi, penerimaan (reception) dan mendengar (overhearing)[6]. Karena adanya keterbatasan energi terdapat kemungkinan terjadi putusnya komunikasi di tengah jalan pada path dikarenakan kehabisan energi. Pada penelitian ini diusulkan adanya proses perhitungan energi pada suatu node yang dapat digunakan sebagai rute baru yang berbasis energi dengan memanfaatkan perubahan topologi. Energi disini merupakan kekuatan aliran listrik yang digunakan dalam transfer paket data yang dinyatakan dengan satuan joule. Efisiensi energi pada routing protocol dapat dilakukan dengan menggunakan metode EA-SHORT (Energy aware - Self Healing and Optimizing Routing Techniques). Tujuan utama dari algoritma EA-SHORT adalah untuk menghemat energi pada MANET, dengan cara memperpanjang masa pakai node dan jaringan dengan merutekan paket melalui node yang memiliki sisa daya yang cukup dan menghindari node yang memiliki daya rendah. Sehingga dapat meningkatkan kinerja dan konservasi daya pada MANET.

Penelitian ini melakukan modifikasi pada kerangka protokol routing AOMDV untuk mengoptimalkan rute yang mempertimbangkan aspek energi dengan menggunakan algoritma EA-SHORT. Kinerja AOMDV dengan EA-SHORT akan diukur dari nilai parameter yang telah ditentukan yaitu Packet Delivery Ratio (PDR), throughput dan end-to-end delay (E2D) yang dilakukan pada sejumlah skenario berbeda, dimana pada penelitian ini akan dicari rute manakah yang paling handal di antara rute-rute yang disediakan oleh protokol routing yang digunakan.

\section{Tinjauan Pustaka}

Penelitian terkait sebelumnya adalah mengenai analisis performansi porotokol routing AOMDV dan AODV pada MANET [7]. Pada penelitian tersebut dilakukan perbandingan dan evaluasi protokol berdasarkan parameter uji yaitu PDR, routing overhead, Normalized Routing Load (NRL), throughput dan average delay. Hasil simulasi pada skenario perubahan jumlah node menunjukkan bahwa AODV lebih baik dari AOMDV dilihat dari parameter performansi PDR sebesar $4.71 \%$, throughput sebesar $9.64 \%$, routing overhead sebesar $2936.12 \%$ dan NRL sebesar 2993.27\%. Namun porotokol routing AOMDV memiliki performansi lebih baik dari AODV, dilihat dari parameter performansi average delay sebesar 423.198\% lebih baik. Selanjutnya hasil simulasi pada skenario perubahan kecepatan node juga menunjukkan bahwa AODV lebih baik dari AOMDV dilihat dari parameter performansi PDR sebesar $13.17 \%$, throughput sebesar $16.51 \%$, routing overhead sebesar $1480.17 \%$ dan NRL sebesar $1669.69 \%$. Dan porotokol routing AOMDV memiliki performansi lebih baik dari AODV, dilihat dari parameter performansi average delay sebesar $238.256 \%$ lebih baik. Sehingga dapat disimpulkan protokol routing AOMDV hanya lebih unggul dari segi parameter average delay daripada protokol routing AODV. Persamaan dari penelitian terkait dengan penelitian yang dilakukan yaitu menggunakan protokol routing AOMDV. Sedangkan perbedaan penelitian terkait dengan penelitian yang dilakukan yaitu pada penelitian yang dilakukan menggunakan metode EA-SHORT dan penelitian sebelumnya tidak menggunakan metode.

Penelitian terkait selanjutnya adalah melakukan analisis perbandingan protokol routing, AOMDV dan AOMDV yang telah dimodifikasi dengan penambahan algoritma perhitungan Signal to Noise Ratio (SNR) ke dalam mekanisme pencarian jalur [8]. Pada skenario perubahan besar paket, throughput mengalami peningkatan sebesar $20 \%$, penurunan NRL sebesar $3 \%$, dan penurunan packet loss sebesar $0,37 \%$. Pada skenario perubahan jumlah traffic, throughput mengalami peningkatan sebesar $12 \%$, penurunan NRL sebesar $0,5 \%$, dan penurunan packet loss sebesar $0,21 \%$. Penambahan algoritma Signal to Noise Ratio (SNR) terbukti dapat meningkatkan performansi protokol routing baik itu throughput, NRL dan packet loss yang lebih baik. Persamaan dari penelitian terkait dengan penelitian yang dilakukan yaitu menggunakan protokol routing AOMDV. Sedangkan perbedaan penelitian terkait dengan penelitian yang dilakukan yaitu pada penelitian yang dilakukan menggunakan metode EA-SHORT dan penelitian sebelumnya menggunakan metode SNR.

Penelitian terkait selanjutnya adalah penelitian untuk mengimplementasikan metode perbaikan protokol routing [1]. Di mana penelitian Optimalisasi routing dengan menggunakan metrik yang berbeda seperti panjang lintasan dan pemakaian energi di sepanjang jalur didefinisikan. Kemudian diusulkan sebuah kerangka kerja SHORT untuk MANET. Saat menggunakan SHORT, semua node tetangga 
memantau rute dan mencoba mengoptimalkannya bila ada jalur yang lebih baik. Pada penelitian ini, algoritma SHORT diterapkan untuk protokol routing AODV dan DSR. Algoritma SHORT meningkatkan optimalisasi routing dengan memonitor jalur routing secara terus menerus dan secara bertahap mengarahkan rute untuk lebih optimal. Hasil simulasi menunjukkan bahwa tingkat pengiriman yang lebih tinggi dan network lifetime yang lebih panjang. Tingkat pengiriman naik sekitar $8 \%$ pada AODV-SHORT dan $6 \%$ pada DSR-SHORT, serta overhead mengalami penurunan sekitar $10 \%$. Persamaan dari penelitian terkait dengan penelitian yang dilakukan yaitu algoritma EA-SHORT. Sedangkan perbedaan penelitian terkait dengan penelitian yang dilakukan yaitu pada penelitian yang dilakukan menggunakan protokol routing AOMDV namun penelitian sebelumnya menggunakan protokol routing DSR dan AODV.

Penelitian terkait selanjutnya tentang peningkatan efisiensi yang dilakukan pada protokol routing AOMDV dengan menggunakan metode PA-SHORT di jaringan MANET [4]. Penelitian ini membandingkan kinerja protokol routing AOMDV dengan protokol routing Path Aware-AOMDV (PA-AOMDV). Protokol routing PAAOMDV diperoleh melalui modifikasi kinerja protokol AOMDV dengan algoritma Path Aware SHORT. Algoritma Path Aware SHORT adalah metode untuk mengurangi jumlah hop. SHORT meningkatkan optimisasi rute dengan memantau rute dan mengoptimalkan rute ini yang memiliki jalur yang lebih baik. Kinerja kedua protokol akan dilihat berdasarkan parameter nilai throughput, average E2D, packet delivery ratio, dan routing overhead. Hasil menunjukkan bahwa throughput meningkat untuk 50 node adalah $61,84 \%$ dan untuk 100 node adalah $45,2 \%$, averange E2D menurun untuk 50 node adalah $0,066 \%$ dan untuk 100 node $0,12 \%$, packet delivery ratio meningkat untuk 50 node adalah $60,87 \%$ dan untuk 100 node $82,02 \%$, dan routing overhead menurun untuk 50 node adalah 67,07\% dan 100 node 45,36\%. Persamaan dari penelitian terkait dengan penelitian yang dilakukan yaitu menggunakan simulasi area $500 \mathrm{~m} \times 500 \mathrm{~m}$ dan $1000 \mathrm{~m} \times 1000 \mathrm{~m}$ serta menggunakan protokol routing AOMDV. Sedangkan perbedaannya yaitu pada penelitian yang dilakukan menggunakan algoritma EA-SHORT namun penelitian sebelumnya menggunakan algoritma PA-SHORT.

Penelitian terkait selanjutnya telah dilakukan analisis perbandingan kinerja protokol routing TORA dan TORA dengan menggunakan algoritma SHORT [9]. Hasil simulasi menunjukkan bahwa throughput yang lebih tinggi meningkat hingga $3-50 \%$, E2D yang lebih rendah hingga $50 \%$, delay mengalami penurunan sebesar $50 \%$, penurunan packet loss bervariasi dari 12 $57 \%$, perbaikan energi sekitar $43 \%$, dan lifetime jaringan yang lebih tinggi. TORA yang dimodifikasi mengungguli protokol routing TORA dalam hal throughput, packet loss, end-to-end delay, dan energi. Persamaan dari penelitian terkait dengan penelitian yang dilakukan yaitu menggunakan algoritma EASHORT. Sedangkan perbedaannya yaitu pada penelitian yang dilakukan menggunakan protokol routing AOMDV namun penelitian sebelumnya menggunakan protokol routing TORA.

\section{Metode Penelitian}

\subsection{Diagram Alir Penelitian}

Diagram alir penelitian penelitian ini dapat dilihat pada Gambar 1.

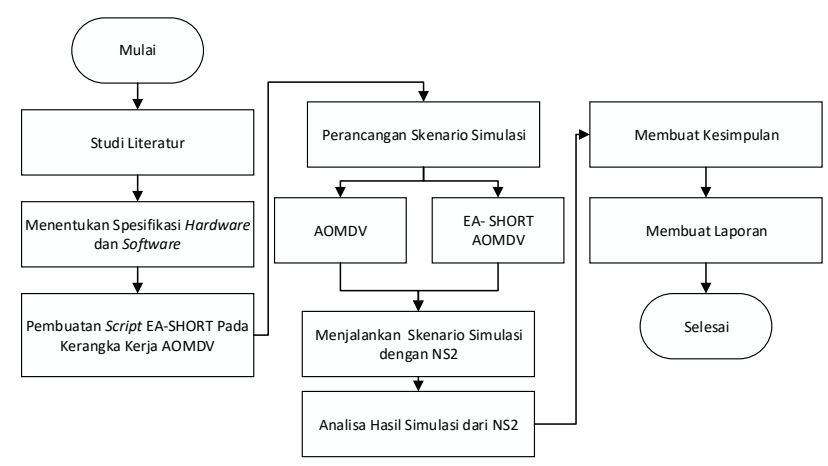

Gambar 1. Diagram Alir Penelitian

\section{a. Studi literatur}

Pada tahap studi literatur, dilakukan pengkajian mengenai berbagai jurnal dan penelitian sebelumnya yang terkait dengan penelitian yang akan dilakukan penulis. Pada tahap ini, dilakukan proses pembelajaran materi penelitian melalui pustaka-pustaka baik berupa buku maupun jurnal ilmiah.

\section{b. Menentukan spesifikasi hardware dan software}

Pada penelitian ini uji coba dan simulasi dilakukan dengan menggunakan Laptop HP 14-bs538TU dengan spesifikasi hardware (perangkat keras) yang dapat dilihat pada Tabel I.

TABEL I. SPESIFIKASI HARDWARE YANG DIGUNAKAN

\begin{tabular}{|l|l|}
\hline Komponen & \multicolumn{1}{|c|}{ Spesifikasi } \\
\hline CPU & $\begin{array}{l}\text { Intel(R) Celeron(R) CPU N3060 } \\
@ 1.60 \mathrm{GHz}\end{array}$ \\
\hline Memori & $\begin{array}{l}4.00 \mathrm{~GB} \text { (2 GB untuk virtual } \\
\text { simulator) }\end{array}$ \\
\hline
\end{tabular}


Hard disk

\section{GB (10 GB untuk virtual}

simulator)

Adapun software yang digunakan pada penelitian ini adalah sebagai berikut :

- Oracle VM VirtualBox 6.0, digunakan untuk menjalankan simulator. Di mana alokasi penggunaan memori komputer yang digunakan sebesar 2 GB dan penggunaan harddisk untuk menyimpan data sebesar 10GB.

- $\quad$ Network Simulator 2 (NS2) versi 2.35 untuk melakukan simulasi MANET.

- Linux Ubuntu 16.04 LTS 64-bit sebagai sistem operasi.

- Microsoft Excel untuk membuat grafik hasil simulasi.

- Microsoft Visio untuk membuat diagram

- Microsoft Word untuk dokumentasi laporan

\section{c. Pembuatan script EA-SHORT AOMDV}

Pembuatan script EA-SHORT AOMDV dilakukan dengan cara memodifikasi kerangka protokol routing AOMDV dengan menyisipkan Algoritma EA-SHORT pada protokol routing AOMDV. Penulisan kode dilakukan melakukan perhitungan berbasis energi pada node untuk menemukan rute hemat energi yang handal. Jika rute telah ditemukan maka jalur tersebut yang akan digunakan untuk melakukan pengiriman data.

\section{d. Perancangan skenario simulasi}

Pada bagian ini, peneliti melakukan perancangan skenario simulasi jaringan MANET untuk melakukan analisis performa algoritma EA-SHORT pada protokol routing AOMDV dengan kondisi, yaitu protokol AOMDV belum menggunakan EA-SHORT dan kondisi dimana AOMDV sudah dimodifikasi menggunakan EA-SHORT.

\section{e. Menjalankan skenario simulasi dengan NS2}

Pada tahap ini perancangan skenario simulasi yang telah dibuat akan dijalankan pada simulator NS2 sehingga diperoleh hasil berdasarkan skenario simulasi yang diujikan. Terdapat beberapa parameter uji yang digunakan untuk melakukan analisa hasil pengujian dari skenario simulasi yang dilakukan yaitu throughput, Packet Delivery Ratio (PDR) dan end to end delay (E2D).

\section{f. Analisis hasil simulasi dari NS2}

Pada tahap ini dilakukan proses analisis terhadap hasil yang diperoleh dari proses pengujian skenario penelitian yang dilakukan, dengan membandingkan hasil simulasi protokol routing AOMDV dan protokol routing EA- SHORT AOMDV dengan percobaan pengiriman data dengan mobilitas node berdasarkan jumlah node, luas area, dan kecepetan node. Menggunakan script AWK akan dianalisis parameter uji yang telah ditentukan. Hasil Analisa simulasi ditampilkan dalam bentuk grafik.

\section{g. Membuat kesimpulan}

Pada tahap ini akan disimpulkan hasil modifikasi protokol routing AOMDV dan pengujian skenario, untuk mengetahui performa terbaik dari skenario yang telah diuji.

\section{h. Membuat laporan}

Pada tahap ini akan dilakukan pembuatan laporan dokumentasi terhadap penelitian yang telah dilakukan. Dokumentasi laporan ini diharapkan agar dapat membantu untuk melakukan penelitian berikutnya.

\subsection{Algoritma Penemuan Rute Menggunakan Protokol Routing AOMDV}

AOMDV merupakan konsep distance vector yakni pencarian rute berdasarkan jarak terdekat dan menggunakan pendekatan hop-by-hop routing[4]. AOMDV menemukan rute berdasarkan permintaan dengan menggunakan prosedur penemuan rute. Keuntungan adanya pada satu kali pencarian rute adalah ditemukannya beberapa rute, jika rute utama mengalami kerusakan maka akan digunakan rute lain yang masih ada pada routing table tanpa harus mencari rute lagi dari awal. Pencarian rute dari awal hanya dilakukan ketika semua rute yang ditemukan sudah tidak valid lagi.

Misalkan, ketika node sumber $A$ akan mengirimkan suatu paket data ke node tujuan $B$, pertama-tama node akan melihat tabel routing apakah sudah ada jalur yang tersedia. Jika jalur dari $A$ ke $B$ sudah tersedia dan siap digunakan, maka paket data akan dikirim menggunakan jalur yang sudah ada tersebut. Jika jalur dari $A$ ke $B$ belum tersedia, maka akan dimulai proses pencarian jalur dengan mengirimkan pesan RREQ secara broadcast. AOMDV menghitung multiple path dan melihat route advertisement untuk menentukan jalur alternatif dari sumber ke tujuan selama proses pencarian jalur. Untuk menghindari kemungkinan loop, digunakan advertised hop count yang ada dalam routing table. Advertised hop count dari sebuah node sumber $A$ untuk tujuan $B$ adalah kumpulan hop count maksimal untuk banyak jalur untuk tujuan B. Advertised hop count dimulai 
setiap ada pembaruan sequence number. Dengan begitu, AOMDV hanya mengambil rute alternatif dengan jumlah hop yang lebih sedikit[10]. Pada AOMDV, propagasi RREQ dari sumber ke tujuan menetapkan beberapa reverse paths baik di node tengah maupun tujuan. Beberapa RREP melintasi lintasan mundur ini untuk membentuk beberapa lintasan maju ke tujuan di node sumber dan tengah. AOMDV juga menyediakan node tengah dengan jalur alternatif karena mereka bermanfaat untuk mengurangi frekuensi penemuan rute[11].

Alur proses route discovery pada protokol AOMDV dapat dilihat pada Gambar 2.

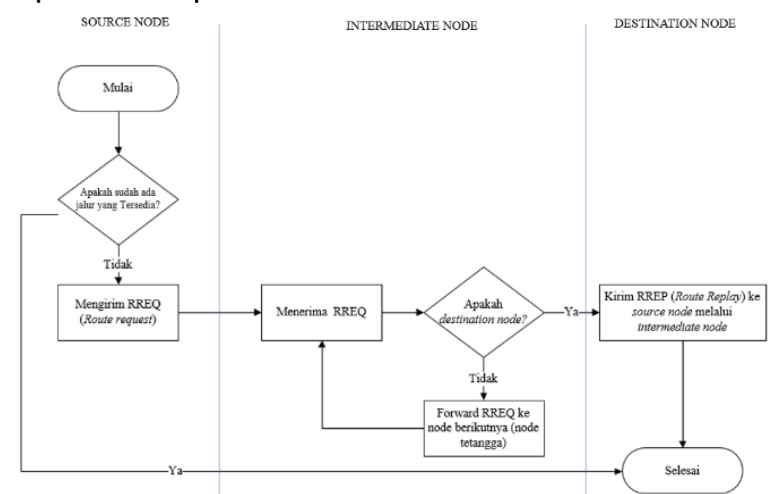

Gambar 2. Flowchart route discovery pada AOMDV

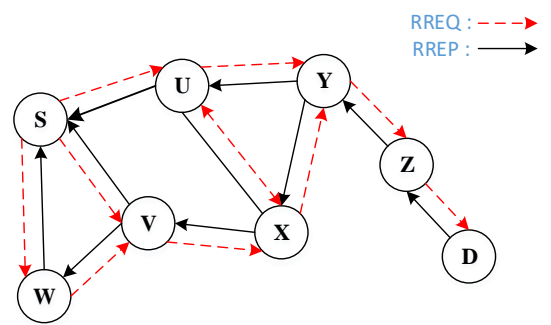

Gambar 3. Proses route discovery pada AOMDV

Proses pencarian rute pada AOMDV dapat dilihat pada Gambar 3, dimana node S merupakan node sumber dan node D merupakan node tujuan. Saat node $\mathrm{S}$ ingin mengirimkan paket ke node $\mathrm{D}$. Pertama kali node S mengirimkan paket RREQ secara broadcast ke node tetangganya yaitu node $\mathrm{U}$, node $\mathrm{V}$ dan node $\mathrm{W}$. Karena node $\mathrm{U}$, node $\mathrm{V}$ dan node $\mathrm{W}$ bukan node tujuannya, maka ketiga node tersebut akan meneruskan paket RREQ secara broadcast ke node tetangganya kecuali source node. Setelah itu node $\mathrm{U}$, node $\mathrm{V}$ dan node $\mathrm{W}$ akan melakukan pengaturan rute cadangan. Proses tersebut akan dilakukan secara terus menerus sampai paket RREQ diterima oleh node tujuannya (node D). Kemudian node D akan memberikan paket RREP sebagai jawaban dari paket RREQ yang diterimanya.

\subsection{Algoritma EA-SHORT}

Tujuan dari penyeimbangan muatan yang sadar energi adalah untuk mendistribusikan secara adil beban lalu lintas di antara semua node yang berpartisipasi di jaringan [1]. Misalnya, pertimbangkan bagian dari MANET ditunjukkan pada Gambar 3.4 (a), jalur S-B-D-F-R adalah jalur optimal untuk koneksi dari $\mathrm{S}$ ke R. Metrik untuk optimalitas dapat berupa jumlah hop untuk rute jalur terpendek. Dengan demikian, node $\mathrm{B}, \mathrm{D}$ dan $\mathrm{F}$ akan terus digunakan dalam meneruskan lalu lintas, meninggalkan node lain bebas dari beban lalu lintas. Akibatnya, tingkat energi residu dari node menjadi sangat bervariasi. Jika perutean tidak sadar energi, itu akan tetap menggunakan jalur untuk koneksi S-R. Node B, D dan F pada akhirnya akan kehabisan persediaan baterai dan mati lebih awal. Namun, skema perutean yang sadar energi akan mencoba mengalihkan lalu lintas ke node lain. Pada penelitian ini diusulkan skema EA-SHORT berdasarkan route redirection (pengalihan rute). Dengan operasi redirection lokal yang berurutan, rute secara bertahap akan konvergen ke rute alternatif node disjoint.

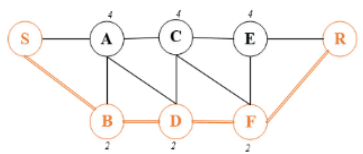

(a) Jalur awal yang menguras energi pada node $\mathrm{B}, \mathrm{D}$ dan $\mathrm{F}$.

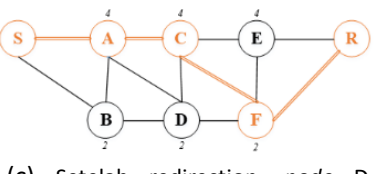

(c) Setelah redirection, node $\mathrm{D}$ diabaikan.

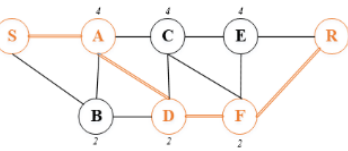

(b) Setelah redirection, node $\mathrm{B}$ diabaikan.

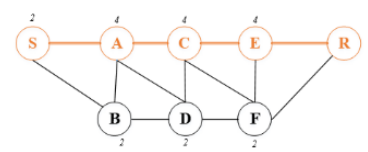

(d) Setelah route redirection, rute baru diabaikan.
Gambar 4. Contoh operator pengalihan rute lokal berturut-turut.

(Tautan yang ditunjukkan pada gambar adalah tautan nirkabel.)

Perhatikan contoh yang ditunjukkan pada Gambar 4 (a), node B, D dan F, ketiganya memiliki tingkat energi yang relatif rendah. Setelah adanya route redirection, node $\mathrm{B}$ diabaikan dan jalur S-B-D-F-R menjadi S-A-D-F$\mathrm{R}$, yang ditunjukkan pada Gambar 3.3 (b). Kemudian, setelah redirection pertama dan seterusnya seperti pada Gambar 3.3 (c) memberikan dampak, jalur S-A-CE-R yang baru akan menggantikan yang asli, seperti yang ditunjukkan pada Gambar 3.3 (d).

Berikut ini langkah-langkah pencarian rute dengan algoritma EA-SHORT. Jika suatu node (i) mengetahui kedatangan paket P. Maka;

a. Node akan melakukan pengecekan rute untuk paket $\mathrm{P}$ pada tabel overhear. Tabel overhear 
merupakan tabel yang digunakan oleh node untuk menyimpan rute suatu paket.

b. Jika tidak ada rute yang cocok. Tambahkan input variabel $e^{\prime}$, dimana rute $\left(e^{\prime}\right)$ sama dengan rute $(p)$, sequence number $\left(e^{\prime}\right)$ sama dengan sequence number $(p)$ lalu jadikan rute $\left(e^{\prime}\right)$ sebagai list rute pertama pada tabel overhear dengan isi $\left(e^{\prime}\right)$ berupa hope count $(p)$, level energi ( $p)$, dan nomer id (p). proses selesai.

c. Misalkan rute (p) ditemukan pada input-an e, dengan kondisi sequence number $(p)$ kurang dari sequence number (e), maka $p$ akan diabaikan, dan proses selesai.

d. Jika sequence number (p) lebih besar dari sequence number pada (e), maka perbaharui e dengan ketentuan yakni sequence number (e) sama dengan sequence number $(p)$, list rute pada tabel overhear (e) direset sehingga memiliki satu input-an rute dengan isi hope count (p), level energi (p). nomer id (p) dan proses selesai.

e. Jika sequence number (p) sama dengan sequence number (e), maka:

1. Tambahkan input-an $\langle\mathrm{hc}(\mathrm{p})$, Ivl (p), nid (p)> ke ov-list (e).

2. Jika daftar overhear pada (e) memiliki tiga input-an yakni A,B,C yang memenuhi kondisi berikut, maka subpath ditemukan.

- Hope count pada (C) sama dengan hope count (B)+1 dan sama dengan hope count $(\mathrm{A})+2$

- Level energi pada (node i) lebih besar atau sama dengan jumlah maksimal energi pada ((A) dan level energi pada (C));

- level energi pada (node i) - level energi (B) $\geq 2$, maka akan diaktifkan sub-rute baru, dan hapus input-an (e) dari tabel overhear.

3. Jika daftar overhear pada (e) memiliki dua input-an, yakni $A$ dan $B$, dengan kondisi hope count (B) sama dengan hope count (A)+1 dan level energi pada node ( $\mathrm{C}) \geq$ maksimal level energi (A) dan dan level energi (B)+2, tambahkan indikator I pada daftar tunggu indikator (Waiting Indicator List), dengan kandidat (I) sama dengan $\mathrm{B}$. sequence number (I) disamakan dengan (e). rute (I) sama dengan rute (e), maka proses selesai.

4. Jika daftar overhear (e) memiliki dua inputan B dan C, dengan kondisi hope count (C) sama dengan hope count (B)+1 dan level energi pada node (i) $\leq$ dari maksimal level energi pada (B)+2 dan level energi (C), maka node I akan menyebarkan pesan SHORT untuk menginformasikan paket $Q$ dengan ketentuan kandidat (Q) sama dengan $B$, sequence number pada ( $Q$ ) sama dengan sequence number pada (e), dan rute (Q) sama dengan rute pada (e).

Ketika node i menerima paket informasi pesan SHORT Q, maka:

- Bandingkan bidang Q dengan input-an yang valid dalam WaitingIndicator list.

- Jika tidak ada yang cocok, maka abaikan paket Q;

Jika kondisi tidak terpenuhi, maka subrute yang lebih baik ditemukan. Aktifkan subrute ini dengan memperbaharui tabel routing.

f. Proses selesai.

Untuk lebih jelasnya, pencarian rute menggunakan algoritma EA-SHORT ditunjukkan pada Gambar 3.5 dan Gambar 3.6.

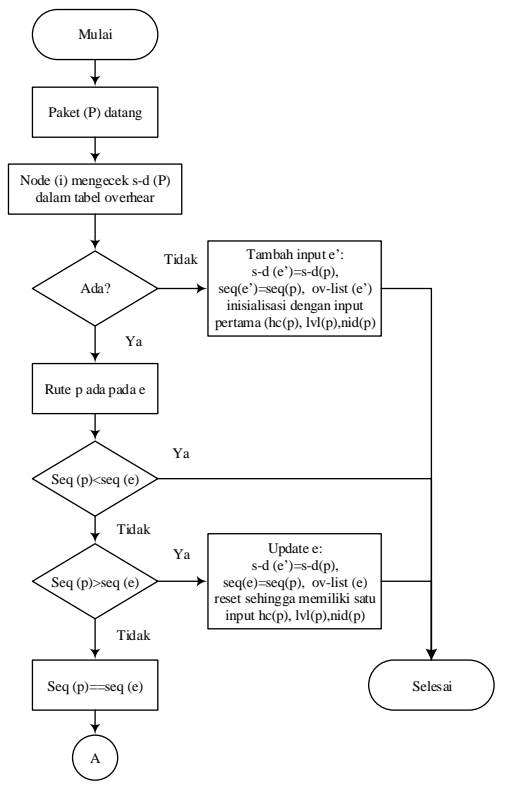

Gambar 5. Flowchart algoritma EA-SHORT 


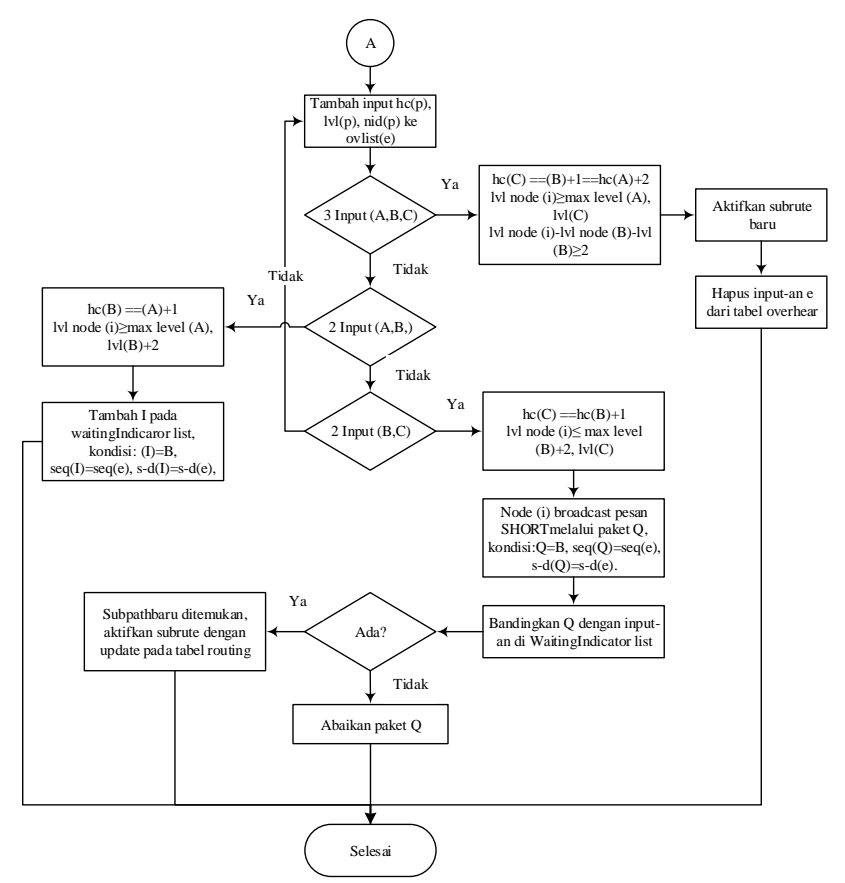

Gambar 6. Flowchart algoritma EA-SHORT (Lanjutan Gambar 5)

\subsection{Lingkungan Simulasi}

Lingkungan simulasi pada penelitian ini akan diterapkan pada protokol routing AOMDV dan protokol routing AOMDV yang telah dimodifikasi dengan algoritma EA-SHORT. Pada penelitian ini simulasi dilakukan dengan menggunakan Network Simulator 2 (NS-2). Pada NS-2 dibutuhkan pola traffic, skenario mobilitas node dan script tcl. Pola traffic mendefinisikan koneksi antara source node dengan destination node dan tipe koneksi yang digunakan (UDP). Skenario mobilitas node mendefinisikan posisi awal node dalam topologi jaringan, kecepatan mobilitas node dan tingkat mobilitas node. Script tcl merupakan kode program yang berfungsi untuk menciptakan objek simulator, mendefinisikan topologi jaringan, load pola traffic dan load skenario mobilitas node. Hasil simulasi dari performa protokol routing AOMDV dan protokol routing AOMDV yang telah dimodifikasi akan dibandingkan dengan menggunakan parameter pengujian yang telah ditentukan.

\section{a. Parameter Pengujian}

Adapun beberapa parameter uji yang digunakan untuk menganalisa hasil pengujian dari skenario simulasi yang dilakukan yaitu:

1. Throughput : Kecepatan (rate) jumlah paket data yang berhasil diterima di sisi penerima pada tiap detik[14]. Semakin tinggi nilai throughput maka semakin handal suatu jaringan, hal ini dikarenakan paket data yang berhasil diterima semakin meningkat. Throughput dihitung menggunakan persamaan (1).

Throughput $(\mathrm{Kbps})=\frac{\text { ukuran data yang dikirim }}{\text { total waktu pengiriman data }}$ (1)

2. Average E2D : rata-rata jeda yang terjadi pada saat pengiriman paket dari pengirim ke penerima paket. Semakin turun nilai Average E2D pada suatu jaringan maka semakin bagus jaringan, karena hal tersebut dapat menghemat penggunaan energi yang dipakai untuk proses routing selama waktu jeda. Average E2D dihitung menggunakan persamaan (2).

Average delay $(\mathrm{s})=\frac{\text { total delay }}{\text { total paket yang diterima }}$

*Di mana delay sama dengan waktu diterima dikurangi waktu dikirim.

3. Packet Delivery Ratio (PDR) : perbandingan paket yang dapat diterima. Semakin tinggi nilai PDR maka semakin baik, hal ini dikarenakan jumlah paket yang gagal diterima semakin berkurang. PDR dihitung menggunakan persamaan (3). Packet Delivery Ratio (\%)

$$
=\frac{\text { paket data yang diterima }}{\text { paket data yang dikirim }} \times 100 \%
$$

\section{b. Parameter skenario simulasi}

Pada bagian ini merupakan skenario uji coba yang akan diimplementasikan menggunakan NS-2 versi 2.35. Link layer yang digunakan adalah berdasarkan pada standar IEEE 802.11. Fungsi koordinasi terdistribusi IEEE 802.11 untuk nirkabel LAN digunakan sebagai lapisan MAC. Jumlah node yang ada pada area sebanyak 50 dan 100 node[4]. Simulasi dilakukan pada area persegi (network area) dengan ukuran $500 \times 500$ $\mathrm{m}^{2}$ dan $1000 \times 1000 \mathrm{~m}^{2}$ [4]. Tujuan simulasi dilakukan pada dua luas area yang berbeda adalah untuk mengetahui perbandingan kinerja kedua protokol dalam keadaan luas area yang kecil dan besar. Waktu simulasi yang dilakukan selama 600 second. Digunakan variasi kecepatan node untuk melihat perbandingan kinerja kedua protokol, serta menggunakan variasi pause time selama $45 \mathrm{~s}, 90 \mathrm{~s}$, dan $180 \mathrm{~s}$ untuk mengetahui perbandingan kinerja kedua protokol. Jenis mobilitas yang digunakan pada simulasi adalah Random Waypoint. Setiap node secara independen memilih destination yang hendak dituju secara acak di dalam batasan jaringan. Parameter skenario simulasi yang lebih lengkap dapat dilihat pada TABEL II.

TABEL II PARAMETER SKENARIO

\begin{tabular}{|l|l|}
\hline \multicolumn{2}{|c|}{ Parameter Skenario } \\
\hline MAC layer & IEEE 802.11 \\
\hline
\end{tabular}




\begin{tabular}{|l|l|}
\hline Jumlah node & 50 node, 100 node \\
\hline Network area & $500 \times 500 \mathrm{~m}^{2}, 1000 \times 1000 \mathrm{~m}^{2}$ \\
\hline Waktu simulasi & $600 \mathrm{~s}$ \\
\hline Kecepatan node & $1 \mathrm{~m} / \mathrm{s}, 5 \mathrm{~m} / \mathrm{s}, 10 \mathrm{~m} / \mathrm{s}$ \\
\hline Pause time & $45 \mathrm{~s}, 90 \mathrm{~s}, 180 \mathrm{~s}$ \\
\hline Pergerakan node & Random Waypoint \\
\hline Propagation & TwoRayGround \\
\hline Antena & Omni antenna \\
\hline Pola traffic & CBR \\
\hline Channel & Wireless \\
\hline
\end{tabular}

\section{4. hasil dan Pembahasan}

\subsection{Analisis throughput}

Skenario uji coba pertama adalah mencari ratarata jumlah paket data yang berhasil diterima di sisi penerima setiap detiknya (throughput). Throughput adalah rata-rata data yang dikirim dalam suatu jaringan. Throughput merujuk pada besar data yang dibawa oleh semua traffic jaringan dan selalu dikaitkan dengan bandwidth.

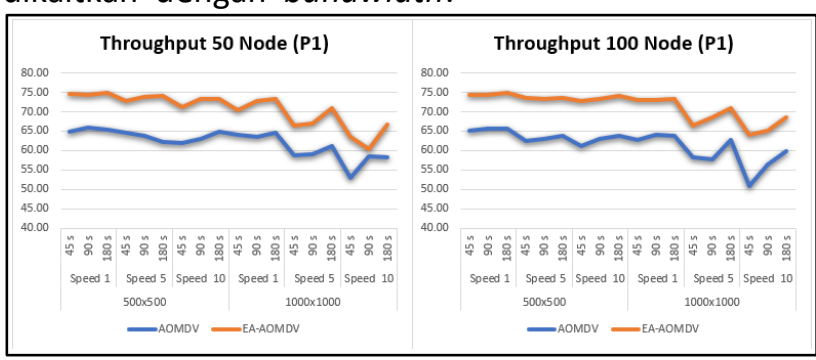

(a)

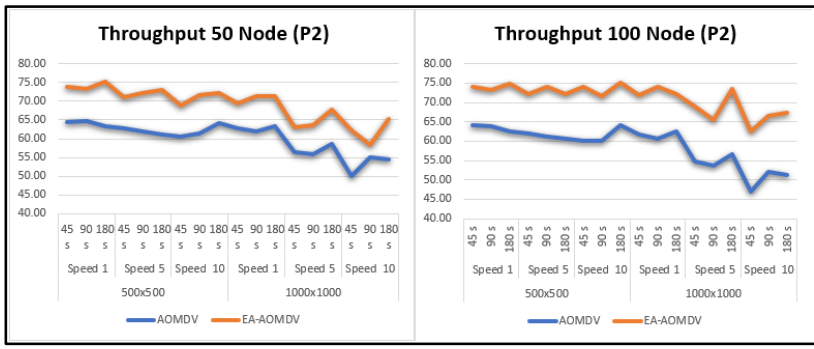

(c)

(d)

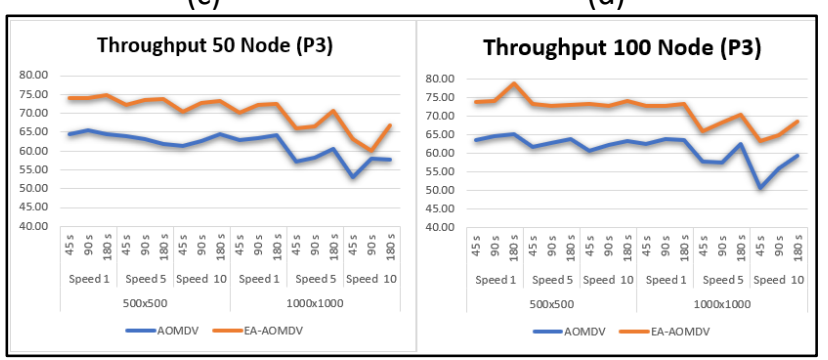

(e) (f)
Gambar 7. Grafik perbandingan nilai throughput pada 3 percobaan. (a) Node 50 percobaan 1; (b) Node 100 percobaan 1; (c) Node 50 percobaan 2; (d) Node 100 percobaan 2; (e) Node 50 percobaan 3; (f) Node 100 percobaan 3
Berdasarkan ketiga percobaan yang dilakukan, rata-rata hasil uji coba throughput pada luas area $500 \times 500 \mathrm{~m}^{2}$ untuk 50 node pada EA-AOMDV adalah 73,04 Kbps dan 63,44 Kbps pada AOMDV. Sedangkan rata-rata hasil uji coba untuk 100 node pada EAAOMDV adalah 73,76 Kbps dan 62,94 Kbps pada AOMDV. Rata-rata hasil uji coba pada luas area $1000 \times 1000 \mathrm{~m}^{2}$ untuk 50 node pada EA-AOMDV adalah 67,13 Kbps dan 59,11 Kbps pada AOMDV. Sedangkan rata-rata hasil uji coba untuk 100 node pada EAAOMDV adalah 69,12 Kbps dan 58,15 Kbps pada AOMDV.

Pengiriman paket data oleh throughput dapat dipengaruhi oleh paket RREQ yang dikirimkan seperti jumlah node yang menentukan kepadatan lalu lintas untuk sampai ke node tujuan atau kecepatan transfernya. Pada grafik Gambar 4.18 nilai throughput dengan pause time 45s relatif selalu turun dan naik pada saat berada di kondisi pause time 180s, perubahan signifikan dapat dilihat di network area $100 \times 1000 \mathrm{~m}^{2}$. Hal ini disebabkan oleh adanya kemungkinan jarak antara node sumber dengan node tujuan yang sangat jauh di luas area yang besar. Ketika node sumber dan node tujuan saling bergerak berjauhan maka akan mengakibatkan semakin banyak rute yang terputus dan mengakibatkan proses pergantian rute semakin sering dilakukan. Pada percobaan ini semakin tinggi pause time, maka semakin lama waktu yang dibutuhkan tiap node untuk tetap stabil sebelum pergerakan node berikutnya.

Selain itu pada grafik terlihat nilai throughput pada node 100 relatif lebih tinggi dibandingkan node 50 terutama nilai EA-AOMDV. Adanya penambahan jumlah node menyebabkan nilai throughput pada protokol AOMDV mengalami peningkatan, hal ini disebabkan oleh banyak node yang terdapat pada lingkungan simulasi akan menetukan kepadatan lalu lintas jaringan sehingga semakin kecil kemungkinan terjadinya link terputus pada jalur komunikasi dan menyebabkan lifetime jaringan bertahan lebih lama.

Berdasarkan grafik hasil uji coba yang telah dilakukan, pada ketiga percobaan dapat diketahui bahwa nilai throughput yang di peroleh pada EAAOMDV selalu lebih tinggi dibandingkan AOMDV standar. Hal ini disebabkan oleh algoritma EA- SHORT mampu meminimalisir terjadinya link failure dengan membandingkan node-node tetangga dari suatu node asal dan memilih node dengan energi paling tinggi untuk menghindari node kehabisan energi di tengah sebelum sampai pada node tujuan. Jadi berdasarkan grafik pada Gambar 7 nilai throughput pada protokol 
routing AOMDV dengan diterapkan algoritma EASHORT memberikan peningkatan nilai sebesar 10 , $2245 \mathrm{Kbps}$, Ini membuktikan protokol routing EAAOMDV lebih baik dari segi throughput jika dibandingkan dengan AOMDV.

\subsection{Analisis Packet Delivery Ratio (PDR)}

Skenario uji coba kedua adalah mencari nilai perbandingan antara paket data yang terkirim dengan jumlah paket data yang dikirimkan oleh node sumber. Packet Delivery Ratio (PDR) menunjukkan keberhasilan protokol dalam mengirim data, tinggi nilai PDR salah satunya disebabkan oleh berhasilnya sebuah protokol dalam melakukan pencarian dan pemeliharaan rutenya.

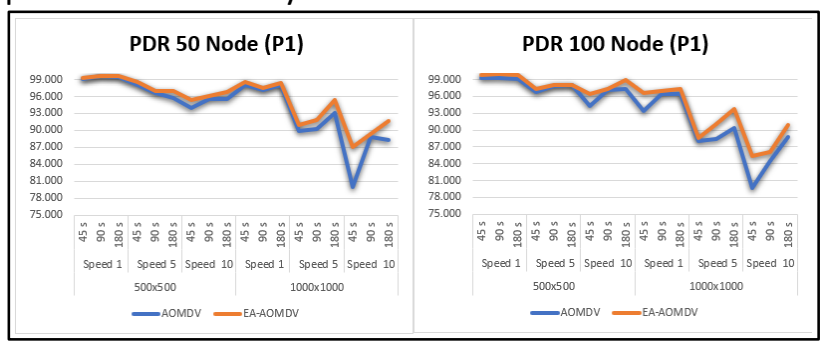

(a)

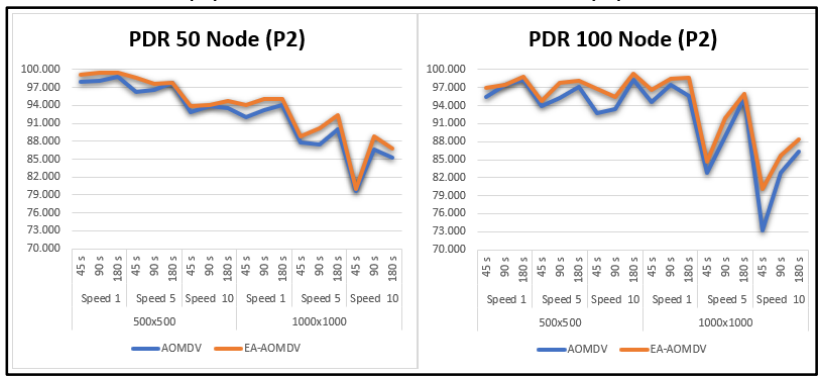

(c)

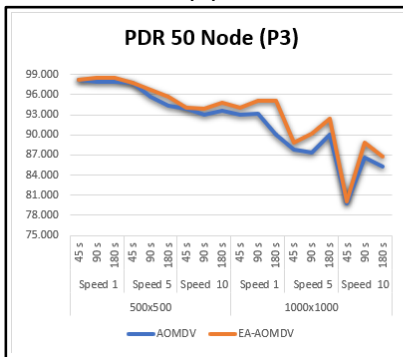

(e) (d)

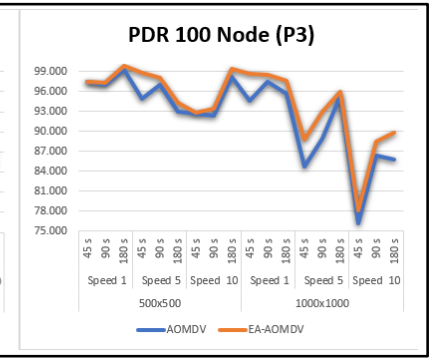

(f)
Gambar 8. Grafik perbandingan nilai packet delivery ratio pada 3 percobaan. (a) Node 50 percobaan 1; (b) Node 100 percobaan 1; (c) Node 50 percobaan 2; (d) Node 100 percobaan 2; (e) Node 50 percobaan 3; (f) Node 100 percobaan 3

Berdasarkan ketiga percobaan yang dilakukan, rata-rata hasil uji coba packet delivery ratio pada luas area $500 \times 500 \mathrm{~m}^{2}$ untuk 50 node pada EA-AOMDV adalah 97,258 \% dan 96,368 \% pada AOMDV. Sedangkan rata-rata hasil uji coba untuk 100 node pada EA-AOMDV adalah 97,513\% dan 96,631\% pada AOMDV. Rata- rata hasil uji coba pada luas area $1000 \times 1000 \mathrm{~m}^{2}$ untuk 50 node pada EA-AOMDV adalah 91,870 \% dan 89,797 \% pada AOMDV. Sedangkan rata-rata hasil uji coba untuk 100 node pada EA-AOMDV adalah 91,512 \% dan 89,417 \% pada AOMDV.

Pada protokol routing AOMDV dan EA-AOMDV pause time mempengaruhi pegerakan node, semakin sering node bergerak, maka zona yang terbentuk akan semakin sering berubah hal tersebut menyebabkan proses penemuan rute semakin sering dilakukan. Seperti terlihat pada grafik Gambar 8 nilai packet delivery ratio pada pause time 45 s selalu mengalami penurunan. Selain itu semakin tinggi kecepatan node, maka packet delivery ratio yang dihasilkan semakin rendah. Dapat dilihat pada grafik saaat kecepatan node menunjukkan angka tertinggi yaitu $10 \mathrm{~m} / \mathrm{s}$ nilai packet delivery ratio semakin menurun terlebih pada pause time $45 \mathrm{~s}$. Hal ini terjadi karena kecepatan gerak node yang meningkat sehingga sering terjadi perubahan posisi node, yang menyebabkan rute yang akan dilalui untuk mengirimkan paket juga akan semakin cepat berubah karena rute mengalami putus link, sehingga terjadi hilangnya paket data yang lewat (packet drop). Perubahan signifikan dapat dilihat di network area $100 \times 1000 \mathrm{~m}^{2}$. Hal ini disebabkan oleh adanya kemungkinan jarak antara node sumbe dengan node tujuan sangat jauh di luas area yang besar, sehingga membutuhkan banyak node untuk mengirim paket data.

Berdasarkan grafik hasil uji coba yang telah dilakukan, pada ketiga percobaan dapat diketahui bahwa nilai packet delivery ratio yang di peroleh pada EA-AOMDV relative lebih tinggi dibandingkan AOMDV standar. Jadi berdasarkan grafik pada Gambar 8 nilai throughput pada protokol routing AOMDV dengan diterapkan algoritma EA-SHORT memberikan peningkatan nilai sebesar 1, 48464\%. Ini membuktikan protokol routing EA-AOMDV lebih baik dari segi packet delivery ratio jika dibandingkan dengan AOMDV.

\subsection{Analisis average end-to-end delay}

Skenario uji coba ketiga adalah mencari nilai rata-rata selang waktu mulai dari paket dikirimkan oleh node sumber sampai paket data tersebut berhasil diterima oleh node tujuan. 


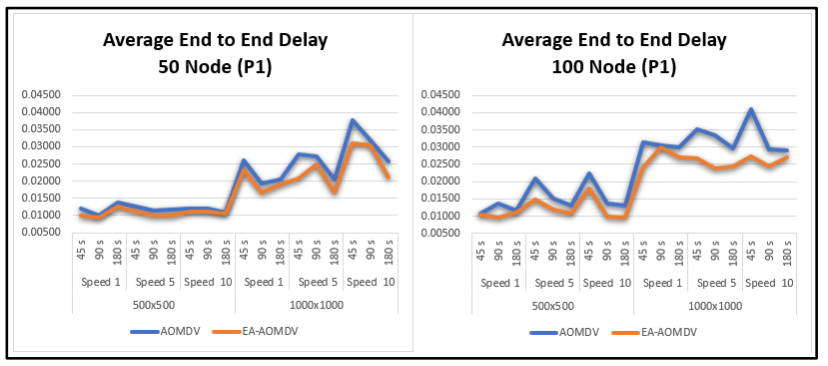

(a)

(b)

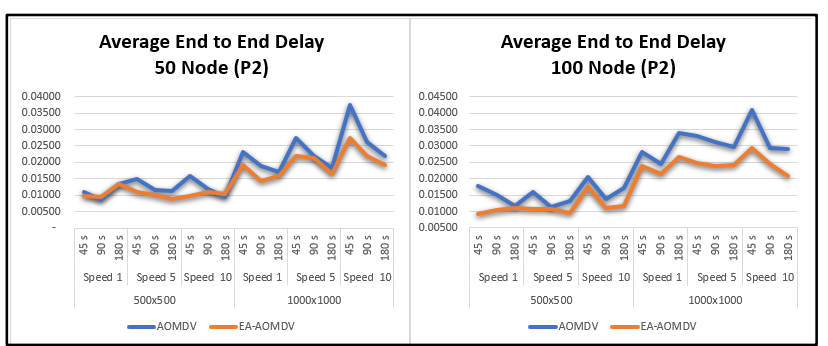

(c)

(d)

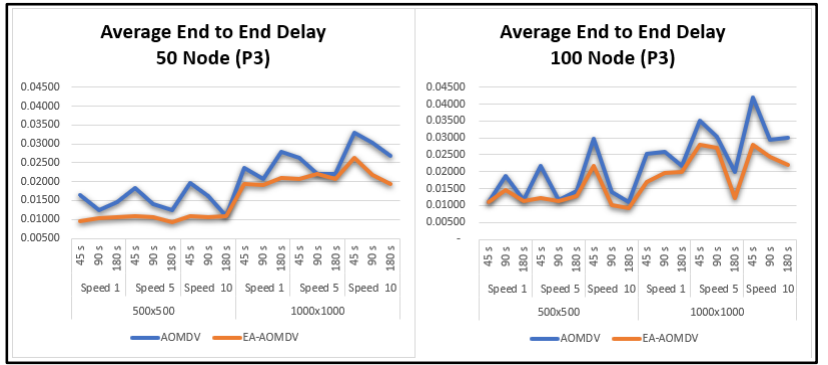

(e)

(f)

Gambar 9. Grafik perbandingan nilai end-toend delay pada 3 percobaan. (a) Node 50 percobaan 1; (b) Node 100 percobaan 1; (c) Node 50 percobaan 2; (d) Node 100 percobaan 2; (e) Node 50 percobaan 3; (f) Node 100 percobaan 3

Berdasarkan ketiga percobaan yang dilakukan, rata-rata hasil uji coba average E2D pada luas area 500 x $500 \mathrm{~m}^{2}$ untuk 50 node pada EA- AOMDV adalah 0,01048 s dan 0,01291 s pada AOMDV. Sedangkan rata-rata hasil uji coba untuk 100 node pada EAAOMDV adalah 0,01196 s dan 0,01536 s pada AOMDV. Rata-rata hasil uji coba pada luas area $1000 \times 1000$ $\mathrm{m}^{2}$ untuk 50 node pada EA- AOMDV adalah 0,02117 s dan 0,02526 s pada AOMDV. Sedangkan rata-rata hasil uji coba untuk 100 node pada EA-AOMDV adalah 0,02418 s dan 0,03072 s pada AOMDV. Nilai E2D yang dihasilkan protokol routing EA-AOMDV lebih rendah dibandingkan dengan protokol routing AOMDV. Ini membuktikan protokol routing EA-AOMDV lebih baik dari segi average E2D jika dibandingkan dengan AOMDV.

Dalam proses pengiriman paket data, terdapat banyak faktor yang mengakibatkan delay. Salah satunya terjadi ketika jumlah komunikasi bertambah akibat kepadatan node, kepadatan node dapat menyebabakn semakin banyak node perantara yang terpakai untuk mengirimkan layanan dari sumber ke tujuan sehingga waktu pengiriman semakin lama. Hal ini dapat dilihat dari nilai rata-rata keseluruhan average E2D pada jumlah 100 node selalu lebih tinggi dibanding nilai average E2D pada jumlah 50 node. Hasil nilai average end-to-end delay yang dihasilkan pada percobaan 1, percobaan 2, dan percobaan 3 terdapat beberapa perubahan yang signifikan pada luas area $1000 \times 1000 \mathrm{~m}^{2}$ untuk protokol routing AOMDV. Hal ini disebabkan oleh adanya kemungkinan jarak antara node sumber dengan node tujuan sangat jauh di luas area yang besar, sehingga membutuhkan banyak node untuk mengirim paket data.

Adanya penerapan algoritma EA-SHORT pada protokol routing AOMDV terbukti dapat menurunkan nilai delay. Hal ini dikarenakan algoritma EA-SHORT meningkatkan optimasi routing dengan melakukan perhitungan energi sehingga memperkecil kemungkinan rute terputus sebelum node sumber sampai pada node tujuan. Pada Gambar 9 hasil menunjukan nilai E2D pada protokol routing AOMDV tanpa menggunakan algoritma dibandingkan dengan nilai E2D pada protokol routing dengan menggunakan algoritma EASHORT terbukti dapat menurunkan hasil delay sebesar $0.04115 \mathrm{~s}$, sehingga dapat dikatakan uji coba pada penelitian ini berhasil.

\section{KeSIMPULAN DAN SARAN}

\subsection{Kesimpulan}

Berdasarkan hasil penelitian yang telah dilakukan dapat diambil kesimpulan sebagai berikut :

a. Berdasarkan hasil uji coba penelitian, penerapan algoritma EA-SHORT mampu meningkatkan performa protokol AOMDV. Di mana setelah penerapan algoritma EA-SHORT, rata-tata throughput mengalami peningkatan sebesar 13,92 $\%$, PDR sebesar $1,57 \%$ dan average E2D menurun sebesar $19,53 \%$.

b. Pada protokol routing AOMDV dan EA-AOMDV pause time dan kecepatan node mempengaruhi pegerakan node. Semakin tinggi pause time dan rendah kecepatan node, maka semakin lama waktu yang dibutuhkan tiap node untuk tetap stabil sebelum pergerakan node berikutnya. Semakin rendah pause time dan tinggi kecepatan node, semakin sering node bergerak, maka rute yang terbentuk akan semakin sering berubah hal tersebut menyebabkan proses penemuan rute semakin sering dilakukan sehingga menyebabkan 
penurunan pada nilai throughput dan packet delivery ratio dan kenaikan pada nilai end-to-end delay.

c. Perubahan signifikan nilai parameter uji selalu terjadi pada network area $1000 \times 1000 \mathrm{~m}^{2}$. Hal ini disebabkan oleh adanya kemungkinan jarak antara node sumber dengan node tujuan yang sangat jauh di luas area yang besar. Ketika node sumber dan node tujuan saling bergerak berjauhan akan mengakibatkan semakin banyak rute yang terputus dan mengakibatkan proses pergantian rute semakin sering dilakukan.

\subsection{Saran}

Berdasarkan penelitian yang telah dilakukam, maka peneliti dapat memberikan saran-saran sebagai berikut :

a. Melakukan penelitian selanjutnya dengan menggunakan protokol routing dan algoritma energy aware yang berbeda pada jaringan MANET.

b. Melakukan penelitian selanjutnya dengan menggabungkan algoritma EA-SHORT dengan algoritma lainnya untuk mencari hasil yang lebih optimal.

c. Melakukan penelitian dengan menggunakan luas area simulasi yang bervariasi dan jumlah kepadatan node dan parameter uji lainnya yang bervariasi pula, untuk mendapatkan hasil yang valid terkait dengan pengaruh luas area, pause time, kecepatan node dan jumlah koneksi terhadap simulasi penelitian di jaringan MANET.

\section{Daftar PUSTAKa}

[1] C. Gui and P. Mohapatra, "A framework for selfhealing and optimizing routing techniques for mobile ad hoc networks," Wirel. Networks, vol. 14, no. 1, pp. 29-46, 2008.

[2] A. Z. I Made Windra Yudistiana, Andy Hidayat Jatmika, "Analisis Optimasi Kinerja Protokol
Routing AODV Dan AOMDV Dengan Menggunakan Metode RFAP Untuk Mencegah RREQ Flooding Attacks Pada Jaringan MANET," Jtika, vol. 1, no. 1, pp. 9-18, 2019.

[3] I. Aulia, F. A. Yulianto, and A. Herutomo, "Analisis Performansi Routing Protocol AOMDV dan DYMO pada Vehicular Ad Hoc Network," pp. 1-6, 2013.

[4] Y. P. Wulandari, A. H. Jatmika, and F. Bimantoro, "Meningkatkan Efisiensi Rute Pada Protokol Routing AOMDV Menggunakan Metode PASHORT," Jtika, vol. 1, no. 1, pp. 77-85, 2019.

[5] A. H. Jatmika, S. Djanali, and M. Husni, "Optimasi Routing pada Jaringan MANET," pp. 1-7, 2011.

[6] W. A. Rachman, P. H. Trisnawan, and M. A. Fauzi, "Analisis Konsumsi Energi Protokol Routing Fisheye State Routing ( FSR ) Pada Mobile Ad Hoc Network ( MANET )," vol. 3, no. 5, pp. 4455-4466, 2019.

[7] A. Fauzio, N. M. Adriansyah, and L. V. Yovita, "Analisis Performansi Ad-Hoc On-Demand Multipath Distance Vector Routing (AOMDV) dan Ad-Hoc On-Demand Distance Vector Routing (AODV) Pada MANET," pp. 1-8, 2007.

[8] L. F. Z. Fauzi, "Analisis Performansi Multipath Routing Pada Jaringan Mobile Adhoc," Telkom University, 2016.

[9] R. Asokan, A. M. Natarajan, and C. Venkatesh, "Quality-of-Service Routing Using Path and Power Aware Techniques in Mobile Ad Hoc Networks," J. Comput. Syst. Networks, Commun., vol. 2008, no. 160574, pp. 1-7, 2008.

[10] A. B. Prasetio, "Analisis Performansi Multipath Routing Pada Jaringan Mobile Adhoc," Universitas Telkom, 2006.

[11] M. K. Marina and S. R. Das, "Ad hoc on-demand multipath distance vector routing," Wirel. Commun. Mob. Comput., vol. 6, no. 7, pp. 969988, 2006. 